MATEC Web of Conferences 25, 02016

(2015)

DOI: $10.1051 /$ matecconf/ 20152502016

(C) Owned by the authors, published by EDP Sciences, 2015

\title{
Research on Synthesis of New Azo Calix[4]arene and its Dyeing Properties
}

\author{
Jun Tang \\ School of Chemical Engineering and Technology, Wuhan University of Science and Technology, Wuhan, Hubei, \\ China \\ Department of Chemical \& Pharmacy Engineering of Huaxia College, Wuhan University of Technology, Wuhan, \\ Hubei, China
}

Yu Sun, Lingling Li, Zhen Xu \& Zaosheng Lv*

School of Chemical Engineering and Technology, Wuhan University of Science and Technology, Wuhan, Hubei, China

ABSTRACT: With the raw materials of calix[4] arene, benzocaine, tricaine and procaine hydrochloride, three new azo calix[4] arene derivatives - $6 \mathrm{a}, 6 \mathrm{~b}$ and $6 \mathrm{c}$ are synthesized by diazotization-coupling reaction of an aromatic amine, with its yield of $83 \%, 81 \%$ and $83 \%$ respectively. The structural characterization is in a way of IR, ${ }^{1} \mathrm{H}$ NMR and elemental analysis. This paper investigates the spectral properties of azo calix[4]arene derivatives under different solution $\mathrm{pH}$ conditions through the UV-visible spectroscopy, and researches the dyeing properties through the dyeing curve, color yield test and fastness test. The results show that, with the increase of $\mathrm{pH}$ value, the azo calix[4]arene derivatives - $6 \mathrm{a}, 6 \mathrm{~b}$ and $6 \mathrm{c}$ form azo-hydrazone tautomeric isomers with the maximum absorption peak redshift; the dyeing effect of the compound is good, of which the dye-uptake rate of the compound $6 \mathrm{a}$ is as high as $78 \%$; the surface depth of color yield is 2.798 , and the dry and wet rubbing fastness and the soaping fastness are respectively 4 , which is a better disperse dye.

Keywords: azo calix[4]arene; diazotization-coupling reaction; azo-hydrazone tautomeric isomers; dyeing

\section{INTRODUCTION}

Disperse dye is currently the largest species in the production of dyes, which is often used in dyeing for polyester fiber and acetate fiber. The development of new disperse dyes with excellent dyeing properties and expansion of its scope of application have important practical significance.

Calixarenes is the third generation of supermolecule after crown ether and cyclodextrin ${ }^{[1]}$, which is a cyclic oligomer connected with a phenol unit by methylene. It is characterized by adjustable cavity, convertible conformation, easy chemical modification and functionalization, easy synthesis, inexpensive raw materials and so on ${ }^{[2]}$. In recent years, with in-depth study of host-guest chemistry, the functional modification and application of the calixarenes become a popular research topic in this field ${ }^{[3]}$. The chromophoric group has become one of the research directions on the functional modification of the calixarenes. By using the diazotization-coupling of the aromatic amine ${ }^{[4]}$, the oxidation-coupling of phenol aromatic ring ${ }^{[5]}$ and other methods, the azo group can be introduced into the calixarene to constitute a host molecule with the color recognition function. Currently, the compound of azo group calixarene mainly contains nitrophenylazo calix[4]arene [6], phenylazo calix[6]arene ${ }^{[7]}$, bis azo group bridged calix[8]arene ${ }^{[8]}$, thiazolyalzo calix[n]arene ${ }^{[9]}$, methylisoxazole azo group calix[4]arene ${ }^{[10]}$ and thiadiazole azo group calix[4]arene ${ }^{[11]}$. Such compound has the nature of the calixarene and azo compounds, which is a type of dye, indicator and heavy metal complexing agent with special selectivity. This paper directly makes the azo group calix[4]arene as a dye, and such article is rarely reported. It is not only of great significance to the development of new disperse dyes with excellent dyeing properties, but also opens up a new application field for the disperse dyes.

In this paper, we synthesize the tert-butyl calix[4]arene with the raw materials of the tert-butyl phenol and formaldehyde, and then synthesize the calix[4]arene with the raw materials of the tert-butyl calix[4]arene after the dealkylation reaction in the presence of the anhydrous aluminum chloride, and finally synthesize three new derivatives of azo group calix[4]arene through the diazotization-coupling action of the aromatic amines. The synthetic route is shown in Figure 1, and the structural characterization is in a way of IR, ${ }^{1} \mathrm{H}$ NMR and elemental analysis. This paper investigates the impact of the solution $\mathrm{pH}$ on the spectral properties of the synthetic compounds via UV-Vis, analyzes the changes of hydrazone form in the azo-hydrazone tautomeric isomers under different $\mathrm{pH}$ values, and researches dyeing process under acidic and alkaline conditions, and researches the

*Corresponding author: 1zs1961@yahoo.com.cn

This is an Open Access article distributed under the terms of the Creative Commons Attribution License 4.0, which permits unrestricted use, distribution, and reproduction in any medium, provided the original work is properly cited. 


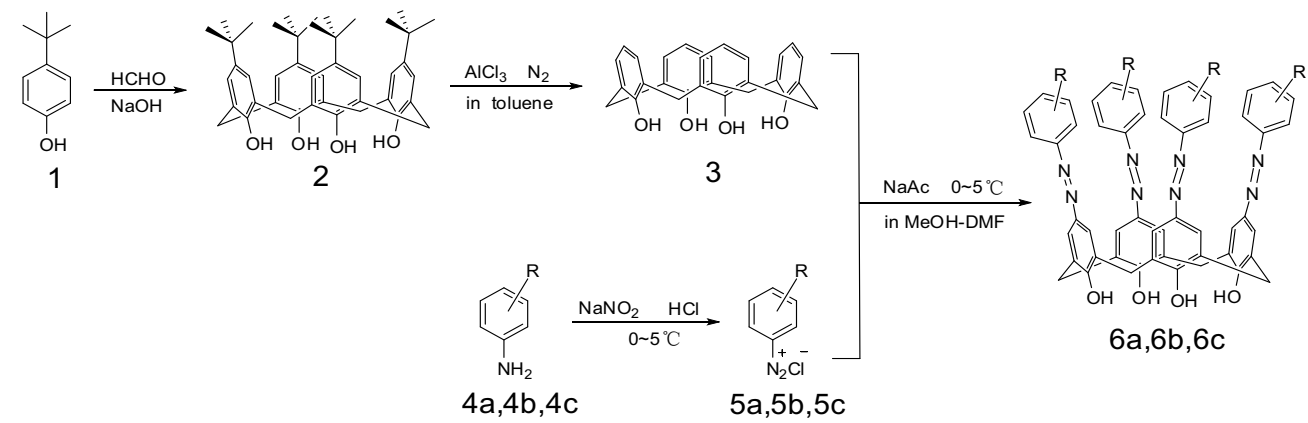

$\mathrm{a}: \mathrm{R}=p-\mathrm{COOCH}_{2} \mathrm{CH}_{3} \quad \mathrm{~b}: \mathrm{R}=m-\mathrm{COOCH}_{2} \mathrm{CH}_{3} \quad \mathrm{c}: \mathrm{R}=p-\mathrm{COOCH}_{2} \mathrm{CH}_{2} \mathrm{~N}\left(\mathrm{CH}_{2} \mathrm{CH}_{3}\right)_{2}$

Figure 1. Synthetic route of the azo group calix[4]arene $(6 a-6 c)$

dyeing properties through the dyeing curve, color yield test and fastness test.

\section{MATERIALS AND METHODS}

\subsection{Material, instrument and agents}

Material: polyester fabric

Instrument: INOVA 600NB hydrogen NMR; VarioIII elemental analyzer; VERTEX 70 Fourier transform infrared spectrometer; UV-visible absorption spectrometer ultrospec 3000 pro.

\subsection{Experiment}

\subsubsection{Synthesis of tert-butyl calix[4]arene and ca-} lix [4]arene

Refer to the references $[12,13]$ to synthesize the tert-butyl calix[4] arene, and refer to the reference ${ }^{[14]}$ to synthesize the calix[4]arene.

\subsubsection{General method of synthesis of Compound 5}

The method is to weigh $10 \mathrm{mmol}$ of aminobenzoate to be dissolved in $10 \mathrm{ml}$ of methanol-water (methanol: water $=1: 1$ ), and add $2 \mathrm{ml}$ of concentrated hydrochloric acid, and cool it to $0^{\circ} \mathrm{C}-5^{\circ} \mathrm{C}$, and then weigh $0.7 \mathrm{~g}$ of sodium nitrite $(10 \mathrm{mmol})$ to be dissolved in $3 \mathrm{ml}$ of water (cool it to $0^{\circ} \mathrm{C}-5^{\circ} \mathrm{C}$ ), and dropwise add the sodium nitrite to the former solution through stirring and ice-bath. The entire process is controlled at $0^{\circ} \mathrm{C}-$ $5^{\circ} \mathrm{C}$, the reaction time is $30 \mathrm{~min}$, so as to obtain $5 \mathrm{a}$ diazonium salt solution. The Congo red test paper can be used to test the acidity, and the potassium iodide test paper can be used to test the nitrite. There is also a need to properly adjust the acidity and add the sodium nitrite.

2.2.3 General method of synthesis of Compound 6 The method is to slowly add aforementioned synthesized diazonium salt to the cold solution $\left(0^{\circ} \mathrm{C}-5^{\circ} \mathrm{C}\right)$, of which containing $1.0 \mathrm{~g}(2.36 \mathrm{mmol})$ of the tetracarbonyl calixarene and $4.08 \mathrm{~g}(30 \mathrm{mmol})$ of sodium acetate trihydrat $-36 \mathrm{ml}$ of methanol-DMF-water $(5: 8: 5 \mathrm{v} / \mathrm{v} / \mathrm{v})$, and then separate out the red precipitate. The ice-bath time is $2 \mathrm{~h}$, the still standing is $2 \mathrm{~h}$ at room temperature, and then the way is suction filtration, washing with water and drying. Recrystallization is done in methanol chloroform.

(6a) 5, 11, 17, 24-4[(4-ethoxycarbonyl-phenyl) azo group] $-25,26,27,28$ - tetrahydroxy-calix[4]arene

The yield is $83 \%$, and the melting point is more than $300^{\circ} \mathrm{C}$. IR, $v / \mathrm{cm}^{-1}: 3331(-\mathrm{OH}), 1718(\mathrm{C}=\mathrm{O}), 1464$

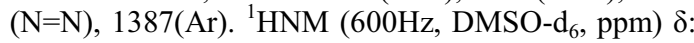
8.04-8.05 (d, $J=6 \mathrm{~Hz}, 8 \mathrm{H}, \mathrm{ArH}), 7.82-7.84(\mathrm{~d}, J=12 \mathrm{~Hz}$, $16 \mathrm{H}, \mathrm{ArH}), 4.31-4.35\left(\mathrm{~d}, 24,8 \mathrm{H}, \mathrm{ArCH}_{2} \mathrm{Ar}\right), 3.41(\mathrm{~m}$, $\left.8 \mathrm{H}, \mathrm{OCH}_{2}\right) 1.31-1.34\left(\mathrm{t}, J=18 \mathrm{~Hz}, 12 \mathrm{H}, \mathrm{CH}_{3}\right)$. Through elemental analysis, the measured value of $\mathrm{C}_{64} \mathrm{H}_{56} \mathrm{~N}_{8} \mathrm{O}_{12}$ is as follows: $\mathrm{C}$ is 68.13 ; $\mathrm{H}$ is 4.97 ; $\mathrm{N}$ is 9.96. The calculated value is as follows: $\mathrm{C}$ is $68.07 ; \mathrm{H}$ is $5.00 ; \mathrm{N}$ is 9.92 .

(6b) $5,11,17,24-4[(3-$ ethoxycarbonyl-phenyl) azo group]-25, 26, 27, 28-tetrahydroxy-calix[4]arene

The yield is $81 \%$, and the melting point is more than $300^{\circ} \mathrm{C}$. IR, $v / \mathrm{cm}-1: 3227(-\mathrm{OH}), 1713(\mathrm{C}=\mathrm{O}), 1548$ $(\mathrm{N}=\mathrm{N}), 1464(\mathrm{Ar}) .{ }^{1} \mathrm{H}$ NM $(400 \mathrm{~Hz}, \mathrm{DMSO}-\mathrm{d} 6, \mathrm{ppm}): \delta$ : 7.84(s, $8 \mathrm{H}, \mathrm{ArH}), 7.61-8.26(\mathrm{~m}, 12 \mathrm{H}, \mathrm{ArH}), 9.24(\mathrm{~s}, 4 \mathrm{H}$, $\mathrm{OH}), 4.30-4.35\left(\mathrm{~m}, 8 \mathrm{H}, \mathrm{OCH}_{3}\right), 1.29-1.33(\mathrm{t}, \mathrm{J}=16 \mathrm{~Hz}$, $\left.12 \mathrm{H}, \mathrm{CH}_{3}\right)$. Through elemental analysis, the measured value is as follows: $\mathrm{C}$ is $68.14 ; \mathrm{H}$ is $4.87 ; \mathrm{N}$ is 9.95 . The calculated value of C64H56N8O12 (Mr, 1129.18) is: $\mathrm{C}$ is $68.07 ; \mathrm{H}$ is $5.00 ; \mathrm{N}$ is 9.92 .

(6c) $5,11,17,24-4[(4-(2-($ diethylamino)) ethoxycarbonyl phenyl) azo group]-25, 26, 27, 28-synthesis of the tetrahydroxy calix[4]arene

The yield is $83 \%$, and the melting point is more than $300^{\circ} \mathrm{C}$. IR, $v / \mathrm{cm}^{-1}$ : $3439(-\mathrm{OH}), 1718(\mathrm{C}=\mathrm{O})$, 1564(N=N), $1412(\mathrm{Ar}) .{ }^{1} \mathrm{H} \mathrm{NM}\left(400 \mathrm{~Hz}, \mathrm{DMSO}^{-} \mathrm{d}_{6}\right.$, ppm) 7.81-8.07(m, 8H, ArH), 6.65-7.00(dd, $12 \mathrm{H}$, $\mathrm{ArH}), 4.43-4.45\left(\mathrm{t}, \mathrm{J}=12 \mathrm{~Hz}, 8 \mathrm{H}, \mathrm{OCH}_{2}\right), 3.60-3.63(\mathrm{t}$, $\left.\mathrm{J}=12 \mathrm{~Hz}, 8 \mathrm{H}, \mathrm{CH}_{2} \mathbf{C H}_{2} \mathrm{~N}\right), 0.97-1.01(\mathrm{t}, \mathrm{J}=16 \mathrm{~Hz}, 12 \mathrm{H}$, $\mathrm{CH}_{3}$ ). Through elemental analysis, the measured value is as follows: $\mathrm{C}$ is $67.94 ; \mathrm{H}$ is 6.59 ; $\mathrm{N}$ is 11.91 . 
The calculated value of $\mathrm{C}_{80} \mathrm{H}_{92} \mathrm{~N}_{12} \mathrm{O}_{12}(\mathrm{Mr}, 1413.66)$ is as follows: $\mathrm{C}$ is 67.97 ; $\mathrm{H}$ is 6.56 ; $\mathrm{N}$ is 11.89 .

\subsubsection{UV absorption spectrum experiment}

Take a certain volume of standard solution of calix[4] arene derivatives to $25 \mathrm{ml}$ of the volumetric flash, add $5 \mathrm{ml}$ of the buffer solution with known $\mathrm{pH}$ value, and dilute the solvents (water, methanol) to the scale and shake up. Take a portion of solution from a $1 \mathrm{~cm}$ pathlength cuvette and place it in the optical path With the reference of corresponding solvents, 200 $800 \mathrm{~nm}$ of wavelength absorption condition can be measured respectively.

\subsubsection{Dyeing}

Take $0.1 \mathrm{~g}$ of dye into the beaker, add $2 \mathrm{ml}$ of DMF and $0.1 \mathrm{~g}$ of dispersants, and then add $100 \mathrm{ml}$ of water in the breaker to adjust the $\mathrm{pH}$ value, and mix up with the glass rod. Pour the evenly stirred dye liquor into the steel bowl and put the polyester base cloth into the steel bowl after moisten it, and then put it into the high-temperature and high-pressure dyeing machine for dyeing $30 \mathrm{~min}$ under the temperature of $130^{\circ} \mathrm{C}$. After dyeing, the fabric is cleaned with the reductive cleaning agent. After the washing, we do soap boiling in a thermostatic water batch shock pan (the soap flake is $3 \mathrm{~g} / \mathrm{L}$; the soda is $3 \mathrm{~g} / \mathrm{L}$; the temperature is $50^{\circ} \mathrm{C}$; the time duration is $45 \mathrm{~min}$; the bath ratio is $1: 50$ ), washing and drying.

\subsubsection{Dye-uptake rate curve}

Dyeing is in accordance with the process conditions. When dyeing begins, the dye-uptake rate shall be measured every $5 \mathrm{~min}$ until the end of dyeing. The dye-uptake rate curve is developed with the dye-uptake rate as the vertical axis, and the time as the horizontal axis:

Dye-uptake rate $=\left(1-\frac{E_{i}}{E_{0}}\right) \times 100 \%$

Where: $E_{i}$ represents the residual night absorbance of dye liquor (dilution factor to be considered); $\mathrm{E}_{0}$ represents the absorbance of dye liquor.

\subsubsection{Color yield depth test}

The value of the surface depth of color yield $(\mathrm{K} / \mathrm{S})$ can be measured by Datecolor 400 computer color testing and matching instrument. The test specimens are folded as four layers. The average value can be obtained by measuring four times.

2.2.8 Soaping fastness, wet/dry rubbing fastness test Please refer to the Standard GB/T 3921-1997 Test Method of Washing Color Fastness of Textiles. The fabric size is $4 \mathrm{~cm} \times 10 \mathrm{~cm}$; the temperature is $60^{\circ} \mathrm{C}$; the time is 30 minutes; the soap powder is $5 \mathrm{~g} / \mathrm{L}$; $\mathrm{Na}_{2} \mathrm{CO}_{3}$ is $2 \mathrm{~g} / \mathrm{L}$; the liquor ratio is $1: 50$. After soaping, ISO grey scale can be used to assess the discoloration of test specimens and staining of adjacent fabric.

Please refer to the Standard GB3920-1997 Test
Method of Color Fastness to Rubbing of Textiles. After testing the parameters, there is a need to remove the testing fiber from the rubbing cloth, and the grey scale is used to assess the staining series of the rubbing cloth.

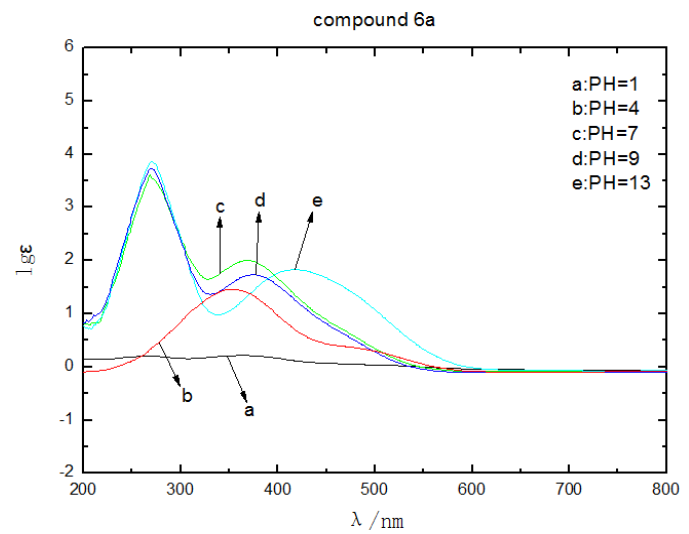

(a)

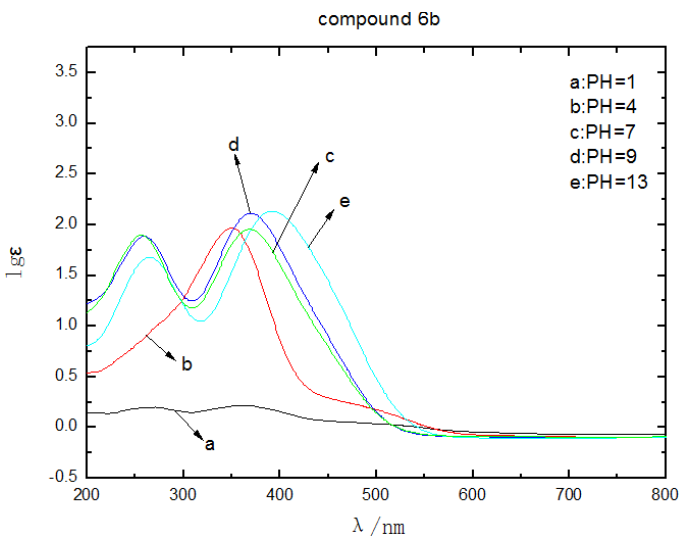

(b)

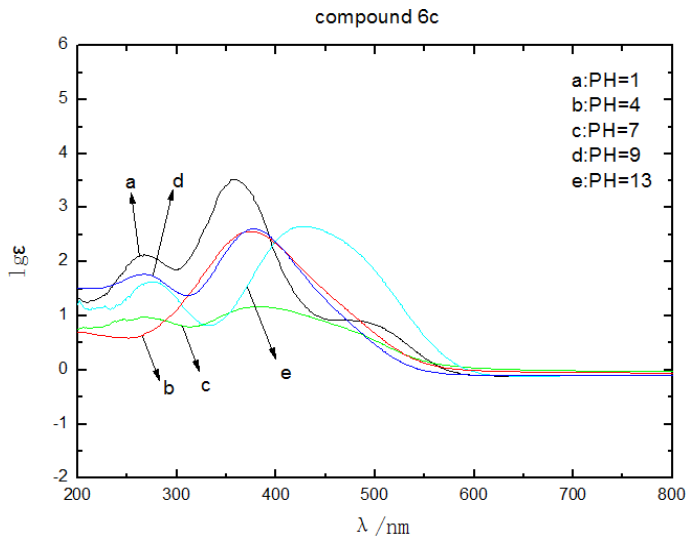

(c)

Figure 2. UV-visible absorption spectrogram of the compound 6 with the changes of $\mathrm{pH}$ value 

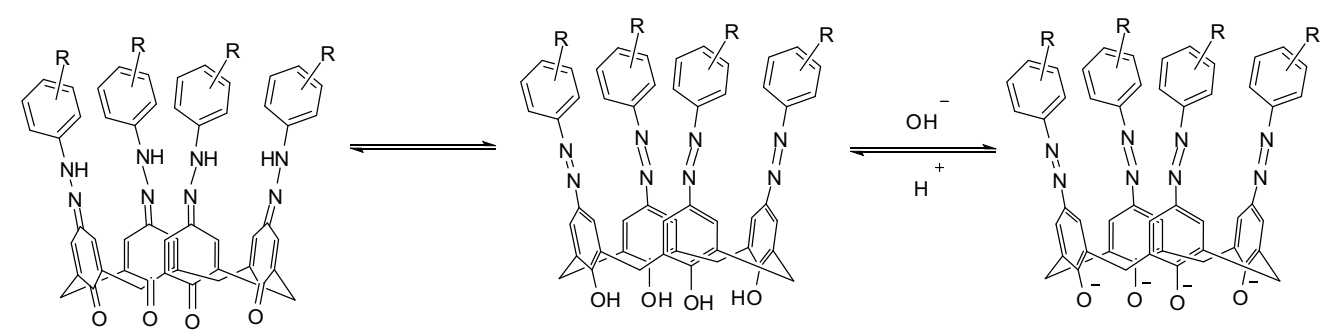

Figure 3. Balanced type of the azo-hydrazone tautomeric isomer of the compound $6 \mathrm{a}$ with the changes of $\mathrm{pH}$ value

Concentration is $5 \times 10^{-5} \mathrm{~mol} / \mathrm{L}, \mathrm{a}: \mathrm{pH}=1 ; \mathrm{b}: \mathrm{pH}=4$; : $\mathrm{pH}=7$; $\mathrm{pH}=9$; e: $\mathrm{pH}=13$

\section{RESULTS AND DISCUSSION}

\subsection{Spectral properties}

The synthesized azo group derivative of the calix[4]arene has multiple phenolic hydroxyl groups $(-\mathrm{OH})$, multiple azo groups $(-\mathrm{N}=\mathrm{N}-), 6 \mathrm{c}$ and multiple tertiary ammonia, so it may have ionization and proton changes under different $\mathrm{pH}$ values, resulting in the changes of visible ultraviolet absorption spectrum. Figure 2 is an ultraviolet absorption spectrogram under different $\mathrm{pH}$ values.

As can be seen from Figure 2, the absorption peak of the compounds $6 \mathrm{a}$ and $6 \mathrm{~b}$ under the strong acid is almost zero; there is only one peak under the weak acid, and two peaks under the neutral, weak base and strong base; with the increase of $\mathrm{pH}$ value, there is the maximum absorption peak redshift. The absorption peak of the compound $6 \mathrm{c}$ under the neutral is almost zero; there is only one absorption peak under the weak acid, three absorption peaks under strong acid, and two absorption peaks under the weak base and strong base; with the increase of $\mathrm{pH}$ value, there is the maximum absorption peak redshift. The absorption peak of 0 is caused by complete precipitation of solid when $\mathrm{pH}$ value of the compounds $6 \mathrm{a}$ and $6 \mathrm{~b}$ is less than 1 , and $\mathrm{pH}$ value of the compound $6 \mathrm{c}$ is 7 .

The azo group calixarene is a kind of calixarene derivative with the most potential to play a significant role in coloration. The azo-hydrazone tautomeric isomer is an important factor to cause coloration, while the acid-base effect has a significant impact on the azo-hydrazone tautomeric isomer $[15,16]$. The azo-hydrazone tautomeric isomer of the azo calix[4]arene $6 \mathrm{a}$ has the following balance with the changes of $\mathrm{pH}$ value (Figure 3 ).

For the compound $6 \mathrm{a}$, it is an azo group under neutral conditions and turns into hydrazone form under the weak acid. In the structure, $-\mathrm{C}=\mathrm{N}$ - occurs $\mathrm{n} \rightarrow \pi$ * transition ${ }^{[17]}$. Under alkaline conditions, the phenolic hydroxyl group in the molecules ionize, namely, $-\mathrm{OH}$ turns into -O-; it makes the oxygen atom increase lone pair electrons, thus greatly enhancing the electronic capability, making the compounds form a larger conjugated system, and leading to the absorption peak redshift.

\subsection{Dyeing properties}

\subsubsection{Dyeing under acidic conditions}

To dye with the high-temperature and high-pressure dyeing machine, $\mathrm{pH}$ value shall be controlled at 5 to 6 . The acetic acid and ammonium dihydrogen phosphate are used to adjust the $\mathrm{pH}$ value. In order to maintain the dye bath to be stable, the dispersants and high-temperature leveling agents are added in dyeing. Dyeing is carried out in the acidic system, and the dyeing process shall measure the dye-uptake rate every five minutes, and the dye-uptake rate curve is developed. The results are shown in Figure 4:

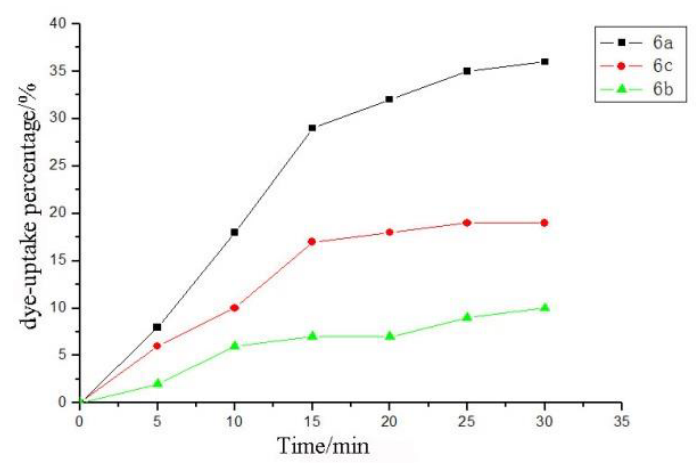

Figure 4. Dye-uptake curve of the compounds $6 a, 6 b$ and $6 c$

As can be seen from Figure 4, the dye-uptake rate of the dyeing system is very low, but the dye-uptake rate of the compound $6 \mathrm{a}$ is higher than that of other compounds.

\subsubsection{Color yield test}

To compare with the dyeing effect of the compounds $6 a, 6 b$ and $6 c$, the color yield parameters $\left(L^{*}, a^{*}, b^{*}\right.$, $\mathrm{c}^{*}, \mathrm{~K} / \mathrm{S}$ ) are shown in Table 1.

In the test data, L, a, b, c values reflect the depth red and green, yellow and blue, and brilliant degree of the fabric color yield. As can be seen from Table 1, the color yield of $6 \mathrm{a}$ is 81.3 , and the brilliant degree is 51.3 with the darkest color and maximum brilliant degree, indicating that the color is close to yellow, K/S 
value is 2.798 with the maximum color yield, while the color yield of $6 \mathrm{~b}$ and $6 \mathrm{c}$ is relatively low, so $6 \mathrm{a}$ is the most suitable as a disperse dye.

Table 1. Color yield test

\begin{tabular}{llllll}
\hline Name & $\mathrm{L}^{*}$ & $\mathrm{a}^{*}$ & $\mathrm{~b}^{*}$ & $\mathrm{c}^{*}$ & $\mathrm{~K} / \mathrm{S}$ \\
\hline $6 \mathrm{a}$ & 81.3 & 5.33 & 51.03 & 51.3 & 2.798 \\
$6 \mathrm{~b}$ & 80.64 & 12.08 & 36.3 & 38.26 & 1.281 \\
$6 \mathrm{c}$ & 69.7 & 13.53 & 28.67 & 31.7 & 1.87 \\
\hline
\end{tabular}

\subsubsection{Fastness test}

The color fastness of the fabric means that the dyed fabric has the ability to maintain the original color state in the process of use or in subsequent processing when the dyes or pigments are affected by a variety of external factors. Its properties determine the application performance and application field of the fabric. Table 2 indicates that the test values of the dry and wet rubbing fastness and the soaping fastness of $6 a, 6 b$ and $6 \mathrm{c}$.

Table 2. Fastness test

\begin{tabular}{llll}
\hline Name & $6 \mathrm{a}$ & $6 \mathrm{~b}$ & $6 \mathrm{c}$ \\
\hline Dry rubbing fastness & 4 & $2-3$ & 3 \\
Wet rubbing fastness & 4 & 3 & $2-3$ \\
Soaping fastness & 4 & $3-4$ & 3 \\
\hline
\end{tabular}

As can be seen from Table 2, the dry and wet rubbing fastness and soaping fastness of the dyed fabric $6 \mathrm{a}$ is 4 which is relatively high, but it is relatively low for $6 \mathrm{~b}$ and $6 \mathrm{c}$, indicating that $6 \mathrm{a}$ can be good for the dyed fabric and dense combination.

\section{CONCLUSIONS}

In this paper, we synthesize three kinds of new azo calix[4]arene dyes through a series of reaction, and adopt the infrared spectroscopy, nuclear magnetic resonance spectrum, elemental analysis and other means to characterize their structures. This paper also adopts the UV-visible spectrophotometry to research the absorption spectral features of these three kinds of derivatives of azo group calixarene under different $\mathrm{pH}$ values, and investigates the relationship between its structure and spectral features, and researches its dyeing properties. The results show that, with the increase of $\mathrm{pH}$ value, the azo calix[4] arene derivatives - $6 \mathrm{a}, 6 \mathrm{~b}$ and $6 \mathrm{c}$ form azo-hydrazone tautomeric isomers with the maximum absorption peak redshift; the dye-uptake rate of the compound $6 \mathrm{a}$ is as high as $78 \%$ with a better color yield test and fastness test, which is suitable as disperse dyes. This research not only has important theoretical significance on the disperse dyes with excellent dyeing properties, but also has practical application value for expanding the application scope of the disperse dyes.

\section{REFERENCES}

[1] Shinkai S. 1993. Calixarenes-The third generation of supramolecules. Tetrahedron, 49(40): 8933-8968.

[2] Adhikari BB, Roshandel S, \& Fujii A, et al. 2015. Calixarene-Mediated Liquid Membrane Transport of Choline Conjugates 2: Transport of Drug-Choline Conjugates and Neurotransmitters. European J Org Chem. (12):2683-2690

[3] Yousaf A, Hamid SA, \& Bunnori NM, et al. 2015. Applications of calixarenes in cancer chemotherapy: facts and perspectives. Drug Des Devel Ther. 9:2831-2838.

[4] Marchand G, Laurent AD, \& Chen Z, et al. 2014. Exceptional stability of azacalixphyrin and its dianion. $J$ Phys Chem A. 118(38):8883-8.

[5] Tóth K, Thu Lan B T, \& Jeney J, et al. 1994. Chromogenic calix[4]arene as ionophore for potentiometric and optical sensors. Talanta, 41(6): 1041-1049.

[6] Yamamoto H, Ueda K, \& Sandanayake K R A S, et al. 1995. Molecular Design of Chromogenic Calix [4] crowns Which Show Very High Na+ Selectivity. Chemistry Letters, (7): 497-498.

[7] Nomura E, Taniguchi H, \& Tamura S. 1989. Selective ion extraction by a calix [6] arene derivative containing azo groups. Chemistry Letters, (7): 1125-1126.

[8] Mohindra Chawla H, \& Srinivas K. 1994. Synthesis of new chromogenic calix [8] arenes. Tetrahedron letters, 35(18): 2925-2928.

[9] Lu Jianquan, \& He Xiwen. 2002. The synthesis of new hosts- thiazoleazo calixarenes derivatives and its application in recognition of heavy metal ions. Chemical Journal of University, 23 (2): 191-194.

[10] Sener I, Karc1 F, \& Kiliç E, et al. 2004. Azocalixarenes. 3: Synthesis and investigation of the absorption spectra of hetarylazo disperse dyes derived from calix[4]arene. Dyes and pigments, 62(2): 141-148.

[11]Chakrabarti A, Chawla H M, \& Francis T, et al. 2006 Synthesis and cation binding properties of new arylazo-and heteroarylazotetrathiacalix[4]arenes. Tetrahedron, 62(6): 1150-1157.

[12] Gutsche C D, \& Iqbal M. 1990. Para-tert-butylcalix [4]arene. Organic Syntheses, 68: 234-237.

[13] Gutsche C D, Levine J A, \& Sujeeth P K. 1985. Calixarenes. 17. Functionalized calixarenes: the Claisen rearrangement route. The Journal of Organic Chemistry, 50(26): 5802-5806.

[14]Kwang H N, \& Gutsche C D. 1982. Calixarenes. 8. Short, stepwise synthesis of p-phenylcalix[4]arene and p-phenyl-p-tert-butylcalix[4]arene and derived products The Journal of Organic Chemistry, 47(14): 2713-2719.

[15] Gordon P F, \& Gregory P. 1983. Organic chemistry in color. Springer-Verlag, 112

[16]Peng Q, Li M, \& Gao K, et al. 1991. Hydrazone-azo tautomerism of pyridone azo dyes: Part II: Relationship between structure and $\mathrm{pH}$ values. Dyes and pigments, 15(4): 263-274 